\title{
Gender Differences and Consumer Videogame Engagement
}

\author{
Abu Bakar Sedek A.Jamak ${ }^{1}$, Amir Zaib Abbasi ${ }^{* 2}$, and Muhammad Shahzeb Fayyaz ${ }^{1}$ \\ ${ }^{1}$ Universiti Teknologi PETRONAS, Department of Management and Humanities, 32610, Bandar \\ Seri Iskandar, Perak, Malaysia \\ ${ }^{2}$ Faculty of Management Sciences, Shaheed Zulfiqar Ali Bhutto Institute of Science and Technology \\ (Szabist), Islamabad, Pakistan
}

\begin{abstract}
This paper intends to examine the gender differences on the engagement states of consumer videogame engagement through comparing the male group vs. female group. To meet this objective, the authors aim to utilize the causal-comparative study to analyse the gender differences on consumer videogame engagement. Data were collected from a sample of 235 teen videogame consumers whose aged were between 16-19years and studying in the private and public universities. Out of 235, the only 219 teen videogame consumers were valid and able to further use for data analysis. Using SPSS 22.0, we examined the valid data through independent t-test and also calculated the effect size for the significant hypotheses. The study findings reported that male teen videogame consumers are significantly different from female teen videogame consumers on the three engagement states of consumer videogame engagement such as cognitive, affective, and behavioural engagement. This paper is first among the videogame studies that has investigated the gender differences on the engagement states of consumer videogame engagement.
\end{abstract}

*Corresponding author: amir_zaib_abbasi@yahoo.co.uk 


\section{Introduction}

Atari Company was the pioneer to develop the Pong game in 1972. The success of Pong game attracted many companies and Atari to develop home-consoles for the firstgeneration such as, the Home Pong, Taito's Gunfight, and Magnavox Odyssey [1]. Since then, each gaming-console generation has brought new developments such as 3D graphics that give rise to the videogame industry [1]. Past researchers reported that videogame has various subgroups that have grown rapidly for example PC games, arcade games and mobile games etc. According to [2] videogame has the ability to attract number of individuals around the globe and engage them in the repetitive playing behavior[3]. Such a behavior compels videogame players to engage in digital gaming and generates their desire to give more time to videogame playing [4].

The term engagement in digital game has been conceptualized as a multidimensional concept $[5,6]$ that can be related with several other theories such as; immersion $[2,3,7]$, flow [8], fun [9], presence [10], enjoyment [11, 12], arousal [13], motivations in videogame play [14], game-engagement [15], user-engagement [16, 17], and consumer videogame engagement $[18,19]$

Through an extant review of literature, it has been evidenced that prior studies have investigated engagement in the following researches such as, Schoenau-Fog [20] examined consumer motives for engagement in digital gaming. Skoric, Teo [4] Conducted another study to investigate the relation between videogame engagement and scholastic accomplishment but the results were insignificant. Brunborg, Mentzoni [21] Examined the impact of videogame involvement on subjective psychological complaints but the results were not up to the mark. Moreover, several researchers have assessed the impact of time an individual spent on playing a game on behavioral issues, academic attainments, drinking and depression but their results were insignificant [22]. Recently, few authors such as Laffan, Greaney [23] have studied the impact of happiness on videogame involvement but the results were not significant. On the other hand, Loton, Borkoles [24] conducted a study in which the authors first examined the relationship between videogame engagement, depression, stress, and anxiety and results showed that videogame engagement has a direct impact on anxiety. The same authors also examined the relationship between videogame addiction, anxiety, depression, and stress and they found that videogame addiction was positively related with stress, anxiety and depression [24].

So far, the existing literature explicated that videogame engagement has been studied with many outcomes such as anxiety, stress and depression, drinking, academic achievement and behavioral conduct issues. However, there is still much to investigate that how gender in terms of male vs. female videogame players can make difference on the engagement in videogame playing? Regarding the proposed research question, we have found only one study that has studied gender differences on game engagement questionnaire [15]. However, authors resulted that there is no significant differences of gender on game engagement questionnaire. In this study, we want to reinvestigate this research question by using another scale of consumer videogame engagement, which is recently developed by $[18,19]$. The main reason behind using this measure is, it has the ability to capture various engagement states such as cognitive, affective, and behavioral engagement in digital games, which no other measures do. Hence, the study's aim is to 
investigate whether gender i.e. male videogame players are significantly different than female videogame players on the three engagement states of consumer videogame engagement.

\section{Research Methodology}

The causal-comparative research design is one of the quantitative approaches. According to Gay, Mills [25] and Salkind [26], the causal-comparative research design allows the researcher to determine the cause, or reason, for existing differences in the behavior or groups. Salkind [26] further added that such differences can be found through utilizing the independent t-test sample. This research design is the most feasible when the study is unable to manipulate the independent variable such as gender, religious preferences, and ethnicity [26]. In this study, we utilized the causal-comparative approach because we had an independent variable, which is based on two established groups such as male or female. On the basis of these groups, the study's aim was to examine how significantly different is the male group through comparing the female group on the dependent variable i.e. consumer videogame engagement. Next, we determined the required sample size for the present study.

We used $\mathrm{G}^{*}$ power 3.0 program [27] to calculate the required sample size for the causalcomparative study. Using the $\mathrm{G}^{*}$ Power program, we gave the following inputs such as, Tests (two independent groups), effect size d (0.5 medium), error prob (0.05), and power (0.95). The $\mathrm{G}^{*}$ Power software resulted that we require the minimum total sample size of 176 comprising 88 on each of the group. In this study, we targeted to collect at least 100 participants on the male and female groups. Afterwards, we used the matching approach to select participants for male and female groups.

According to Salkind [26], matching is one of the approaches to strengthen the research design and counter threats to internal validity and research sample. Employing the matching approach, we selected the participants based on the inclusion criteria as gender (male and female), ethnicity (Chinese, Indian, Malay) and age (16 to 19 years). The teen students were targeted due to the fact that they are still considered as enthusiastic videogame-players today [28].

In order to collect data from male and female groups, the study fully adopted the previous developed scale of consumer videogame engagement that was developed and validated by $[18,19]$. Consumer videogame engagement is a multidimensional construct that comprises cognitive, affective and behavioral engagement. Each engagement state is further measured by two constructs such as conscious attention and absorption measure the cognitive engagement. While dedication and enthusiasm measure the affective engagement. Social connection and interaction measure the behavioral engagement. In this scale, we add two more items of conscious attention such as item 6 from [29] and item 7 from [30]. These items were previously used for analyzing the redundancy analysis [19]. The response categories on consumer videogame engagement comprise the 5 points likert scale such as 1 $=$ strongly disagree, $2=$ disagree, $3=$ neutral, $4=$ agree, $5=$ strongly agree. Besides the scale of consumer videogame engagement, the study also added few demographic 
questions such as gender coded as 1 for male and 2 for female, ethnicity coded as 1 for Malay, 2 for Chinese, and 3 for Indian, and education was measured with 1 for foundation student, 2 for diploma student, and 3 for fresh undergraduate student. Using the measure of consumer videogame engagement, the study used a multistage sampling procedure to collect study subjects.

In the multistage sampling technique, we followed two basic steps as suggested by [31]; the first step is to make listing and second step is make sampling. Firstly, the study generated a list of four major states (Perak, Johor Bahru, Penang, and Selangor) of Malaysia. From the list, we randomly made a selection one state i.e. Perak. Within the Perak state, we made a list of universities from the following website (http://www.malaysiauniversity.net). After listing, we randomly selected two universities one from the public sector and another from the private sector. In each university, the teen students aged 16-19 years, studying in foundation/diploma or 1st year undergraduate programs, were called for participation in the survey. In case of the Universiti Teknlogi MARA, the diploma students of these two faculties (faculty of architecture, planning and survey and faculty of arts and design) were randomly selected to participate in the study survey. While for the Universiti Teknologi PETRONAS, this study has randomly selected the foundation and 1st year undergraduate students of these two faculties (IT and Engineering stream). Once students were selected, we further divided them into two groups based on their gender. Using the classroom environment, we distributed 135 questionnaires to the male group and 115 questionnaires to the female group. In case of the male group, 129 responses and for the female group, 104 responses were returned. Next, we performed the preliminary data analysis on the collected data. We deleted 6 responses from the female group and 8 responses from the male group due to getting biased responses and missing values. After deletion, we left with valid 98 female and 121 male respondents that were further used for data analysis. Table 1 illustrated the demographic information of the respondents.

Table 1. Respondents' profile $(N=219)$

\begin{tabular}{|c|c|c|}
\hline Respondents Profile & $\begin{array}{c}\text { Percentage \% } \\
\text { Male Videogame Players } \\
(\mathbf{N = 1 2 1})\end{array}$ & $\begin{array}{c}\text { Percentage \% } \\
\text { Female Videogame Players } \\
(\mathbf{N = 9 8})\end{array}$ \\
\hline Age (Years) & 14.9 & \\
16 & 15.7 & 13.3 \\
$17-18$ & 69.4 & 18.4 \\
19 & & 68.4 \\
\hline Ethnicity & 40.5 & 39.8 \\
Malay & 44.6 & 44.9 \\
Chinese & 14.9 & 15.3 \\
\hline Indian & & \\
\hline
\end{tabular}




\section{Education}

Foundation

26.4

Student

Diploma

Student

Fresh

Undergraduate

Student
29.6

22.4

48.0

Answers generated in multiple response setting (percent of cases means each percentage is out of 100)

\section{Videogame Genres}

Action

68.3

52.6

Adventure

49.2

Arcade

35.0

Shooter

60.8

Role-Playing

41.7

40.2

Fighting

51.7

42.3

Strategy

70.0

Sports Game

36.7

Racing

45.8

Casual

17.5

30.9

Children'

2.5

Entertainment

7.5

44.3

28.9

Family

17.5

Entertainment

Flight

Other video

games/Genre

\section{Data Analysis}

This study used the t-test because the study aimed to find the significant differences between male and female videogame players in terms of consumer videogame engagement. Gay, Mills [25] debated that the T-test analysis is the right choice of the study due to its ability to examine whether the scores of male videogame players are significantly different from female videogame players. The independent sample t-test was performed by SPSS 22.0 to assess the differences between male vs. female videogame players on the engagement states of consumer videogame engagement. The results showed in the Table 2 was about the group statistics, which explained that male players have higher scores on the three engagement states of consumer videogame engagement than female videogame players. While the Table 3 reported t-test results, which confirmed that male videogame players are significantly different than female players on the three engagement states (cognitive, affective, and behavioral) of consumer videogame engagement.

Additionally, the study also measured the effect size because authors recommended to show the effect size with the results of hypotheses [25]. To calculate the effect size, this study used the online calculator through using the following website (http://www.uccs.edu/lbecker/index.html) given by Becker [32]. To evaluate the effect size whether it is small, medium or large, this study used the Cohen's estimation criteria of the effect sizes as small if " $\mathrm{d}=0.2$ ", medium if " $\mathrm{d}=0.5$ ", and large if “ $\mathrm{d}=0.8$ " [32,33]. In this 
study, we examined the effect size on the significant relationships and found that male videogame players have a large effect on the engagement states of consumer videogame engagement comprising cognitive, affective, and behavioral engagement as compare to female videogame players as shown in the table 4.

Table 2. Group Statistics

\begin{tabular}{|l|l|l|l|l|l|}
\hline Group Statistics & Gender & $\mathrm{N}$ & Mean & $\begin{array}{l}\text { Std. } \\
\text { Deviatio } \\
\mathrm{n}\end{array}$ & $\begin{array}{l}\text { Std. Error } \\
\text { Mean }\end{array}$ \\
\hline $\begin{array}{l}\text { Cognitive } \\
\text { Engagement }\end{array}$ & Male & 121 & 3.6884 & .58925 & .05357 \\
\hline $\begin{array}{l}\text { Affective } \\
\text { Engagement }\end{array}$ & Male & 121 & 3.6099 & .58969 & .05361 \\
\hline $\begin{array}{l}\text { Behavioral } \\
\text { Engagement }\end{array}$ & Male & 98 & 3.0684 & .64322 & .06497 \\
\hline
\end{tabular}

Table 3. T-test

\begin{tabular}{|c|c|c|c|c|c|c|c|c|c|c|}
\hline \multicolumn{11}{|c|}{ Independent Samples Test } \\
\hline & & \multicolumn{2}{|c|}{$\begin{array}{l}\text { Levene's } \\
\text { Test for } \\
\text { Equality of } \\
\text { Variances }\end{array}$} & \multicolumn{7}{|c|}{ t-test for Equality of Means } \\
\hline & & \multirow[t]{2}{*}{$\mathrm{F}$} & \multirow[t]{2}{*}{ Sig. } & \multirow[t]{2}{*}{$\mathrm{t}$} & \multirow[t]{2}{*}{ Df } & \multirow{2}{*}{$\begin{array}{l}\text { Sig. } \\
(2- \\
\text { tailed } \\
\quad)\end{array}$} & \multirow[t]{2}{*}{$\begin{array}{l}\text { Mean } \\
\text { Differe } \\
\text { nce }\end{array}$} & \multirow{2}{*}{$\begin{array}{l}\text { Std. } \\
\text { Error } \\
\text { Differe } \\
\text { nce }\end{array}$} & \multicolumn{2}{|c|}{$\begin{array}{c}\text { 95\% Confidence } \\
\text { Interval of the } \\
\text { Difference }\end{array}$} \\
\hline & & & & & & & & & Lower & Upper \\
\hline \multirow[t]{2}{*}{$\begin{array}{l}\text { Cognitive } \\
\text { Engagement }\end{array}$} & $\begin{array}{l}\text { Equal } \\
\text { variances } \\
\text { assumed }\end{array}$ & .470 & .494 & 6.64 & 217 & .000 & .55773 & .08396 & .39224 & .72322 \\
\hline & $\begin{array}{l}\text { Equal } \\
\text { variances } \\
\text { not } \\
\text { assumed }\end{array}$ & & & 6.57 & $\begin{array}{l}197.8 \\
99\end{array}$ & .000 & .55773 & .08485 & .39040 & .72507 \\
\hline
\end{tabular}




\begin{tabular}{|c|c|c|c|c|c|c|c|c|c|c|}
\hline \multirow[t]{2}{*}{$\begin{array}{l}\text { Affective } \\
\text { Engagement }\end{array}$} & $\begin{array}{l}\text { Equal } \\
\text { variances } \\
\text { assumed }\end{array}$ & .108 & .742 & 6.48 & 217 & .000 & .54155 & .08347 & .37704 & .70606 \\
\hline & $\begin{array}{l}\text { Equal } \\
\text { variances } \\
\text { not } \\
\text { assumed }\end{array}$ & & & 6.42 & $\begin{array}{l}199.3 \\
41\end{array}$ & .000 & .54155 & .08424 & .37544 & .70766 \\
\hline \multirow[t]{2}{*}{$\begin{array}{l}\text { Behavioral } \\
\text { Engagement }\end{array}$} & $\begin{array}{l}\text { Equal } \\
\text { variances } \\
\text { assumed }\end{array}$ & .658 & .418 & 6.68 & 217 & .000 & .59796 & . 08950 & .42155 & .77436 \\
\hline & $\begin{array}{l}\text { Equal } \\
\text { variances } \\
\text { not } \\
\text { assumed }\end{array}$ & & & 6.61 & $\begin{array}{l}198.4 \\
06\end{array}$ & .000 & .59796 & . 09041 & .41967 & .77624 \\
\hline
\end{tabular}

Table 4. Effect Size

\begin{tabular}{|l|c|c|c|c|}
\hline \multicolumn{5}{|c|}{ Effect Size Calculation for Significant Relationships } \\
\hline $\begin{array}{l}\text { Cognitive } \\
\text { Engagement }\end{array}$ & T-Value & P-Value & Effect Size (Cohen $d)$ \\
\hline $\begin{array}{l}\text { Affective } \\
\text { Engagement }\end{array}$ & 6.643 & .000 & $\mathbf{. 9 0}$ & Large Effect \\
\hline $\begin{array}{l}\text { Behavioral } \\
\text { Engagement }\end{array}$ & 6.488 & .000 & $\mathbf{. 8 8}$ & Large Effect \\
\hline
\end{tabular}

\section{Discussion}

This study aimed to investigate whether male videogame players are significantly different than female videogame players on the three engagement states of consumer videogame engagement. The findings of the study reported that male videogame players are more prone to engage cognitively, affectively, and behaviourally in videogame playing than female videogame players. Such a change between male vs. female videogame players on the engagement states of consumer videogame engagement, can be of many reasons. Firstly, male videogame players have more access to gaming world as they can visit to many gaming zones where they can play multiple high graphic games and get an opportunity play games repetitively. On the other hand, female videogame players do not have such access to the gaming zones because Malaysia is the eastern country whereby parents do not allow them to stay outside for longer hours especially, in the gaming zones. Hence, they do not have an opportunity to play high graphic videogames. Secondly, male 
videogame players get more time as compared to female to play videogames because girls have to do some home-chores. Thirdly, female videogame players do not get many opportunities to play different videogames like competitive, role-playing and so on as compared to male group. This is due to the fact that male players can go to their friends' place, cafes and different places to play highly competitive and role-playing games, which in turn gives them more prospect to engage in the videogame playing environment. Although in today's world females are equally empowered but as mentioned above the study conducted in Malaysia, so due to the eastern environment and religious beliefs women do not have a complete freedom to move freely and cannot stay outside the home late at night. Normally parents do not prefer to allow the girls to remain outside the home for long hours. Females can go to markets and gaming zones but with their family members or any male member of their family like brother or father and due to this reason they cannot spend much time in gaming zones. As Malaysia is an Islamic country so majority people are Muslims, so the Islamic beliefs do not allow Muslims to send their females alone outside for playing games and to socialize with others in the gaming zones or cafes in the particular context of study. So due to this reason females have fewer platform available for playing videogames as compared to males and for that reason the mean value in the case of females in Table 2 and Table 3 is lower than the male respondents because women have less chances to play games as compared to males especially in the eastern Islamic countries like Malaysia. To the best of authors' knowledge, there is no study that has investigated gender differences on the three engagement states of consumer videogame engagement. Hence, the findings of this study cannot directly compare with other empirical studies. However, the general results of the present study can be compared with the previous study by Brockmyer, Fox [15] who studied gender differences on game engagement questionnaire. In their results they could not find any significant differences between male and female players on game engagement questionnaire.

\section{Contribution}

The present study negates the previous results that reported that gender makes no difference on game engagement questionnaire. Such a difference between studies can be of many reasons; Brockmyer, Fox [15] targeted age group 12-15years student who play violent content games and the study is conducted in the western culture but in the present study context, authors targeted students aged 16-19years who play any genre of videogames and the study is conducted in the eastern culture. This study is the first among videogame and consumer behaviour studies that have studied gender differences on consumer videogame engagement.

\section{Limitations}

Several limitations attached to the present study is that, it only investigated the phenomenon of gender differences on consumer videogame engagement in Malaysian context. Different countries have different cultures and different dynamics which differentiate it from others. So, a study is required to investigate the gender differences in non-Muslim eastern countries such as China, South Korea, and Japan etc. and in west too in order to generalize the result. Moreover, this study has examined the gender differences in any genres of videogame. A future study is required to investigate the phenomenon of gender differences in different categories of games such as action, adventure, arcade, 
shooter, role-playing, to know about that is there any difference of gender lies in a particular category of game.

\section{Conclusions}

In this study, authors revealed that male videogame players have more propensity than female videogame players to get engaged cognitively, affectively, and behaviorally in the digital game environment. This study is limited to 16-19years aged group and to videogame players who play any kinds of videogames. The study's results are only limited to Malaysian culture. In this study, the research method is limited to causal-comparative approach. This study also opens avenues for future work whereby they can extend the aged group from 16-19years to 19-25years or older aged group. Next studies can target to any specific category of videogames and investigate the gender differences. Besides, future studies can examine potential predictors or consequences of consumer videogame engagement.

\section{Managerial Implications}

This study helps the manager to understand that which gender is more actively involved in the videogame playing. So, managers can easily know their needs and fulfill it in a timely manner. Moreover, with the help of this study videogame developers can enhance their games with good graphics and designed new games according to the customer needs and demands and can earn the high revenues by achieving the desired goals of the companies. This research has been funded through the Short Term Internal Research Fund (STIRF) of Universiti Teknologi PETRONAS, Malaysia. We are really thankful to University for their support.

\section{References}

1. Kuo, A., J.L. Hiler, and R.J. Lutz, From Super Mario to Skyrim: A framework for the evolution of video game consumption. Journal of Consumer Behaviour, 2017. 16(2): p. 101-120.

2. Jennett, C., et al., Measuring and defining the experience of immersion in games. International journal of human-computer studies, 2008. 66(9): p. 641-661.

3. Brown, E. and P. Cairns. A grounded investigation of game immersion. in CHI'04 extended abstracts on Human factors in computing systems. 2004. ACM.

4. Skoric, M.M., L.L.C. Teo, and R.L. Neo, Children and video games: addiction, engagement, and scholastic achievement. Cyberpsychology \& behavior, 2009. 12(5): p. $567-572$.

5. Filsecker, M. and M. Kerres, Engagement as a Volitional Construct A Framework for Evidence-Based Research on Educational Games. Simulation \& Gaming, 2014. 45(45): p. 450-470.

6. Schønau-Fog, H. and T. Bjørner, "Sure, I Would Like to Continue" A Method for Mapping the Experience of Engagement in Video Games. Bulletin of Science, Technology \& Society, 2012. 32(5): p. 405-412.

7. Ermi, L. and F. Mäyrä, Fundamental components of the gameplay experience: Analysing immersion. Worlds in play: International perspectives on digital games research, 2005. 37: p. 2. 
8. Chen, J., Flow in games (and everything else). Communications of the ACM, 2007. 50(4): p. 31-34.

9. Koster, R., Theory of fun for game design. 2013: " O'Reilly Media, Inc.".

10. McMahan, A., Immersion, engagement and presence. The video game theory reader, 2003. 67: p. 86.

11. Mayes, D.K. and J.E. Cotton. Measuring engagement in video games: A questionnaire. in Proceedings of the Human Factors and Ergonomics Society Annual Meeting. 2001. SAGE Publications.

12. IJsselsteijn, W., et al. Measuring the experience of digital game enjoyment. in Proceedings of Measuring Behavior. 2008. Maastricht Netherlands.

13. Ravaja, N., et al., Phasic emotional reactions to video game events: A psychophysiological investigation. Media Psychology, 2006. 8(4): p. 343-367.

14. Przybylski, A.K., C.S. Rigby, and R.M. Ryan, A motivational model of video game engagement. Review of general psychology, 2010. 14(2): p. 154.

15. Brockmyer, J.H., et al., The development of the Game Engagement Questionnaire: A measure of engagement in video game-playing. Journal of Experimental Social Psychology, 2009. 45(4): p. 624-634.

16. O'Brien, H.L. and E.G. Toms, What is user engagement? A conceptual framework for defining user engagement with technology. Journal of the American Society for Information Science and Technology, 2008. 59(6): p. 938-955.

17. O'Brien, H.L. and E.G. Toms, The development and evaluation of a survey to measure user engagement. Journal of the American Society for Information Science and Technology, 2010. 61(1): p. 50-69.

18. Abbasi, A.Z., D.H. Ting, and H. Hlavacs, Engagement in Games: Developing an Instrument to Measure Consumer Videogame Engagement and Its Validation. International Journal of Computer Games Technology, 2017. 2017: p. 10.

19. Abbasi, A.Z., et al., A Revisit of the Measurements on Engagement in Videogames: A New Scale Development, in Entertainment Computing - Icec 2016. 2016. p. 247-252.

20. Schoenau-Fog, H. The player engagement process-an exploration of continuation desire in digital games. in Think Design Play: Digital Games Research Conference. 2011.

21. Brunborg, G.S., et al., Gaming addiction, gaming engagement, and psychological health complaints among Norwegian adolescents. Media Psychology, 2013. 16(1): p. 115-128.

22. Brunborg, G.S., R.A. Mentzoni, and L.R. Frøyland, Is video gaming, or video game addiction, associated with depression, academic achievement, heavy episodic drinking, or conduct problems? Journal of Behavioral Addictions, 2014. 3(1): p. 2732 .

23. Laffan, D.A., et al., The relationships between the structural video game characteristics, video game engagement and happiness among individuals who play video games. Computers in Human Behavior, 2016. 65: p. 544-549.

24. Loton, D., et al., Video game addiction, engagement and symptoms of stress, depression and anxiety: the mediating role of coping. International Journal of Mental Health and Addiction, 2016. 14(4): p. 565-578.

25. Gay, L.R., G.E. Mills, and P.W. Airasian, Educational research: Competencies for analysis and applications. 2011: Pearson Higher Ed.

26. Salkind, N.J., Encyclopedia of research design. Vol. 1. 2010: Sage. 
27. Faul, F., et al., $G^{*}$ Power 3: A flexible statistical power analysis program for the social, behavioral, and biomedical sciences. Behavior research methods, 2007. 39(2): p. 175-191.

28. Lee, D. and R. LaRose, A socio-cognitive model of video game usage. Journal of Broadcasting \& Electronic Media, 2007. 51(4): p. 632-650.

29. Vivek, S.D., et al., A generalized multidimensional scale for measuring customer engagement. Journal of Marketing Theory and Practice, 2014. 22(4): p. 401-420.

30. Qin, H., P.-L. Patrick Rau, and G. Salvendy, Measuring player immersion in the computer game narrative. Intl. Journal of Human-Computer Interaction, 2009. 25(2): p. 107-133.

31. Acharya, A.S., et al., Sampling: Why and how of it. 2013.

32. Becker, L.A., Effect size (ES). 2000.

33. Sullivan, G.M. and R. Feinn, Using effect size-or why the p value is not enough. Journal of graduate medical education, 2012. 4(3): p. 279-282. 